\title{
ПРОГРАММНОЕ ОБУЧЕНИЕ ДЕТЕЙ И ПОДРОСТКОВ ПО СНИЖЕНИЮ МАССЫ ТЕЛА В КОМПЛЕКСНОМ ПОДХОДЕ К ЛЕЧЕНИЮ ОЖИРЕНИЯ В ДЕТСКОМ КОНСУЛЬТАТИВНО- ДИАГНОСТИЧЕСКОМ ЦЕНТРЕ
}

\author{
Трубилина М.М., Гончаренко Е.М., Левченко Н.А., Черняева Т.О., Черняк И.Ю.. \\ ГБУЗ «Детская краевая клиническая больница», г. Краснодар
}

\begin{abstract}
Актуальность. По данным ВОЗ, в 2016 г. в мире от ожирения и избыточного веса страдали 41 млн детей в возрасте по 5 лет и 340 млн детей и подростков в возрасте 5-19 лет. В настоящее время ожирение рассматривается не просто как избыток жировой ткани в организме, а как хроническое рецидивирующее заболевание, тесно ассоциированное с рядом серьезных осложнений. Залогом успешной терапии ожирения, наряду с диетой, физическими нагрузками и медикаментозной терапией, является обучение пациентов. Образовательная программа - это новые информационно-мотивационные технологии, которые способствуют повышению приверженности пациентов к лечению, формируют у них мотивацию к сохранению своего здоровья и повышают ответственность пациента за здоровье как своей личной собственности.
\end{abstract}

Цель. Провести оценку эффективности комплексного программного обучения детей и подростков с ожирением по снижению массы тела в детском консультативно-диагностическом центре.

Материалы и методы. В ГБУЗ ДККБ в 2015 году на базе детского консультативно - диагностического центра создана первая на Кубани «Школа коррекции и профилактики ожирения у детей». Цель обучения - достижение оптимальной массы тела, профилактика развития сопутствующих заболеваний, улучшение качества жизни ребенка. В задачи обучения входят создание и поддержание установки детей на длительное лечение, предоставление пациентам информации о заболевании, об индивидуальных проблемах и путях решения, формирование адекватного отношения больных к заболеванию и оценке собственного состояния, определение индивидуальных целей лечения. Методическое оснащение Школы: наглядный учебный материал, обучающие таблицы, дневник питания для больных, светофор питания, таблица калорийности, анкеты для выявления типа нарушения пищевого поведения, мультимедийное сопровождение занятий. Комплексный подход включает психологическую коррекцию, занятия лечебной физкультурой. Обучение проходило индивидуально, а так же в группах. Программа обучения включала 5 занятий по 1,5-2 часа. Занятия проводились 1 раз в 1-2 недели в амбулаторных условиях. Групповые занятия для детей с 7-ми лет и подростков осуществлялись совместно с родителями. Помимо очного обучения, на сайте ГБУЗ ДККБ создан «Электронный кабинет наблюдения за детьми с избыточной массой тела», обеспечивающий доступность необходимой медицинской информации о профилактике ожирения и его осложнений для пациентов, их родителей, а также для коллег.

Результаты. Программа снижения массы тела включала два этапа: первый - снижение массы тела на протяжении 6 месяцев, второй - удержание достигнутых результатов, и считался эффективным при снижении массы тела более $10 \%$ от исходной. На втором этапе допускается увеличение массы тела не более, чем на 3 кг после первого этапа. Динамическое наблюдение за детьми на первом этапе в программе по снижению массы тела осуществляется 1 раз в месяц, далее на этапе удержания достигнутых результатов контрольный осмотр и консультация проводится не реже, чем 1 раз в 3 месяца и по показаниям.

Регулярные физические нагрузки увеличивали темпы снижения массы тела в 4 раза. Вдвое сократилось число детей со 2 и 3 степенью ожирения, наблюдаемых в Школе. 82\% детей имели положительный результат программы снижения массы. Обучение в школе проводилось бесплатно. За год через школу проходит от 42 до 50 детей от 7 до 18 лет. С января 2021 года проведено 20 занятий, было 4 группы по 5 детей +5 взрослых. За курс 5 занятий потеря веса у каждого ребенка группы 3-5 кг.

Выводы. Таким образом, программно-целевое обучение является эффективным медицинским и психологопедагогическим процессом в составе комплексного подхода к лечению детей и подростков с ожирением. 